\title{
PROTOTYPE SMART HOME DENGAN KONSEP IOT (INTERNET OF THING) BERBASIS NODEMCU DAN TELEGRAM
}

\author{
Siswanto ${ }^{1}$, Thoha Nurhadian $\mathbf{H}^{2}$, Muhamad Junaedi ${ }^{3}$ \\ Program Studi Rekayasa Sistem Komputer - Universitas Serang Raya \\ E-mail:fitrakbar06@gmail.com
}

\begin{abstract}
ABSTRAK
Perkembangan teknologi dibuat untuk menunjang kebutuhan manusia agar lebih praktis dalam kehidupan salah satunya dalam bidang rumah tangga. Hal inilah yang mendasari penelitian ini. Dengan menggunakan NodeMCU sebagai mikrokontroller untuk sistem Smart Home berkonsep IOT. Dengan dibuatnya sistem Smart Home berkonsep IOT ini diharapkan bisa nilai efisiensi dan nilai keamanan dirumah - rumah. Pada penelitian ini NodeMCU diimplementasikan sebagai mikrokontroller pada sistem Smart Home berkonsep IOT. Sistem ini di rancang dengan menggunakan Telegram Messenger sebagai media input ataupun notifikasi pada sistem ini. Ketika input chatting lalu pembacaaan data input chatting oleh program untuk diverifikasi. Jika verifikasi tidak berhasil maka sistem tidak merespon dilanjutkan dengan memprogram ulang input chatting, jika verifikasi berhasil maka BOT akan merespon lalu mengirimkan sinyal input ke mikrokontroller untuk di proses, setelah diproses mikrokontroller akan mengirimkan sinyal output (On/Off) untuk dikirimkan ke relay yang mana akan diteruskan ke komponen output (Solenoid Doorlock, lampu LED, Buzzer). Dengan menerapkan sistem Smart Home berkonsep IOT ini maka kita bisa memanfaatkan teknologi yang ada. Pada sistem Smart Home berkonsep IOT ini juga aman karena hanya orang-orang yang memiliki aksses tertentu yang dapat mengontrol rumah seperti membuka kunci pintu dan menyalakan lampu dari jarak jauh.
\end{abstract}

Kata Kunci: IOT, Smart Home, Telegram Messenger

\section{PENDAHULUAN}

Seiring dengan perkembangan jaman sistem keamanan dan pengontrolan dibutuhkan masyarakat dalam menunjang kehidupan. Dalam kasus lain terkadang kita lupa untuk mematikan lampu, mematikan TV, mematikan AC atau merasa tidak yakin sudah mengunci pintu rumah dan lain-lain ketika sedang berada di luar sehingga kita harus kembali dan melakukan pengecekan yang sangat tidak efesien baik dari sisi waktu ataupun finansial seperti biaya bensin kelokasi rumah, dengan tujuan efisiensi itulah muncul ide yang di sebut dengan Smart Home dengan konsep IOT (Internet of Things). 


\section{Tujuan Penelitian}

Berdasarkan latar belakang permasalahan diatas tujuan dari penelitian ini adalah merancang dan mengimplementasikan sistem keamanan dan penerangan yang dapat dikontrol dari jauh berbasis IOT

\section{LANDASAN TEORI}

\section{Internet Of Things}

Menurut (Burange \& Misalkar, 2015) Internet of Things (IOT) adalah struktur di mana objek, orang disediakan dengan identitas eksklusif dan kemampuan untuk pindah data melalui jaringan tanpa memerlukan dua arah antara manusia ke manusia yaitu sumber ke tujuan atau interaksi manusia ke komputer.

Internet of Things merupakan perkembangan keilmuan yang sangat menjanjikan untuk mengoptimalkan kehidupan berdasarkan sensor cerdas dan peralatan pintar yang bekerjasama melalui jaringan internet (Keoh, Kumar \& Tschofenig,2014).

\section{NODEMCU ESP8266}

NodeMCU merupakan sebuah open source platform IoT dan pengembangan kit yang menggunakan bahasa pemrograman eLua untuk membantu pembuat dalam membuat produk IoT atau bisa dengan memakai sketch dengan arduino IDE. Nodemcu juga memiliki board yang berukuran sangat kecil yaitu panjang $4.83 \mathrm{~cm}$, lebar $2.54 \mathrm{~cm}$, dan dengan berat 7 gram. ESP8266 sendiri merupakan chip WiFi dengan protocol stack TCP/IP yang lengkap.

NodeMCU dapat dianalogikan sebagai board arduino-nya ESP8266. Program ESP8266 sedikit merepotkan karena diperlukan beberapa teknik wiring serta tambahan modul USB to serial untuk mengunduh program. Namun NodeMCU telah me-package ESP8266 ke dalam sebuah board yang kompak dengan berbagai fitur layaknya mikrokontroler + kapabilitas akses terhadap Wifi juga chip komunikasi USB to serial. Sehingga untuk memprogramnya hanya diperlukan ekstensi kabel data USB persis yang digunakan charging smart phone. 


\section{Modul Relay}

Modul relay adalah saklar yang dioperasikan secara elektrik yang memungkinkan untuk menghidupkan atau mematikan sirkuit dengan menggunakan voltase atau arus yang jauh lebih tinggi dari pada yang dapat ditangani oleh NodeMCU. Tidak ada hubungan antara rangkaian tegangan rendah yang dioperasikan oleh NodeMCU dan rangkaian daya tinggi. Relay melindungi setiap rangkaian dari satu sama lain. Setiap saluran dalam modul ini memiliki tiga koneksi bernama NC, COM, dan NO. Bagian NC dan NO relay digunakan untuk menghubungkan sumber listrik (kabel fasa) dengan terminal SPO. Jenis kontak yang digunakan di perangkat ini ialah Normally Closed (NC) sehingga pada kondisi arus normal sambungan sumber ke SPO tertutup. Sedangkan pada saat arus lebih, kontak akan otomatis diputuskan (open) bagian belitan (coil) relay disambungkan ke pin pengendali NodeMCU melalui switch transistor.

\section{Solenoid Door Lock}

Selenoid merupakan suatu komponen elektro yang berkerja berdasarkan sistem elektromagnetis, sehingga didalam selenoid terdapat kawat penghantar yang dililitkan pada inti besi dan solenoid itu sendiri mempunyai sebatang besi yang digunakan sebagai penarik atau tuas. Apabila penghantar yang dililitkan pada inti besi dialiri listrik maka lilitan tersebut mengeluarkan medan magnet sehingga dapat menarik batang besi.

Solenoid merupakan kawat berbahan konduktor yang disusun sehingga membentuk kumparan (koil) dan dapat dialiri arus listrik. Kuat medan magnet di dalam (sumbu) solenoida jauh lebih besar bila dibanding dengan di luar solenoida. Solenoida disebut ideal bila medan magnet di dalam solenoida bersifat homogen dan diluarnya nol.

Selenoid door lock pada alat ini bekerja ketika diberi tegangan 12V. Didalam solenoid terdapat kawat yang melingkar pada inti besi. Ketika arus listrik mengalir melalui kawat, maka terjadi medan magnet untuk menghasilkan energi yang akan menarik inti besi ke dalam. Dan ketika tidak diberi arus listrik maka medan magnet akan hilang dan energi yang menarik inti besi ke dalam akan hilang juga sehingga membuat posisi inti besi ke posisi awal. Keadaan ini dimanfaatkan sebagai pengunci pintu. Peralatan yang dipakai untuk mengkonversikan sinyal elektrik atau 
arus listrik menjadi gerak mekanik. Terdiri dari kumparan dan inti besi yang dapat digerakkan.

\section{Telegram Messenger}

Telegram Messenger adalah aplikasi pesan chatting seperti Whatsapp, Line dan BBM (Blackberry Messengger). Telegram Messenger menggunakan protokol MTProto yang sudah teruji dengan tingkat keamanannya karena proses enkripsi end-to-end yang digunakan. Sama seperti aplikasi sejenis, Telegram Messenger dapat berbagi pesan, foto, video, location tagging antara sesama pengguna.

\section{RANCANGAN SISTEM}

Di bawah ini adalah blok diagram perencanaan dan pembuatan alat yang akan dilakukan mengintegrasi dari berbagai perangkat input, proses dan output. Catu daya, mikrokontroler NodeMCU,

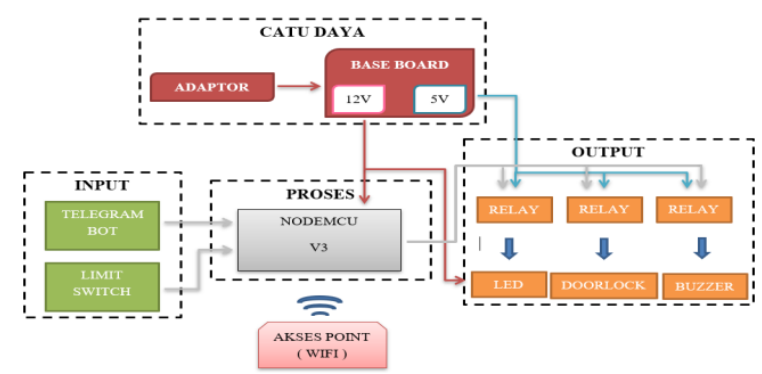

Sumber: Dokumen Pribadi

Gambar 1. Blok Diagram Sistem Keamanan dan penerangan Rumah

Secara garis besar proses yang akan dijalankan pada sistem Smart Home dengan konsep IOT (Internet Of Thing) berbasis NodeMCU dan telegram ini adalah:

1. Proses perancangan prototype.

2. Proses pemograman.

3. Proses pembacaan instruksi.

Cara kerja sistem Smart Home dengan konsep IOT (Internet Of Thing) berbasis NodeMCU dan telegram : 
1. Sumber tegangan input $220 \mathrm{~V}$ dan output adaptor 12 volt mensuplay power ke Mikrokontroller NodeMCU serta komponen - komponen input maupun ouput pada alat ini.

2. User mengakses prototype smart home dengan cara menghubungkan dengan BOT telegram di telegram messenger dengan memasukan perintah - perintah yang sudah di program berupa chatting.

3. User memasukan perintah dan akan diterima oleh BOT telegram.

4. Input dari BOT telegram, sinyal diproses menjadi sinyal output yang mana akan mengaktifkan modul relay untuk mengaktifkan atau menonaktifkan komponnen output seperti lampu, doorlock dan buzzer.

5. Saat komponen output aktif atau nonaktif mikrokontroller menerima feedback yang mana akan di proses menjadi sinyal output untuk dikirimkan kepada BOT telegram sebagai konfirmasi bahwa apa yang sudah diperintahkan telah dilaksanakan.

6. BOT telegram menyampaikan ke user bahwa apa yang di perintahkan tealah dilaksanakan berupa chatting via telegram messenger kepada user.

\section{PENGUJIAN DAN ANALISIS}

pengujian ini adalah untuk menguji kelayakan dan meminimalisasikan kegagalan atau trouble pada rangkaian yang dibuat, untuk mengetahui apakah sistem yang telah direalisasi sesuai dengan perancangan serta memenuhi secara fungsional.

\section{PENGUJIAN}

Pengujian Pengujian alat ini meliputi pengujian perangkat keras dan rangkaian keseluruhan meliputi pengunian perangan input, proses, dan output. 
HASIL PENGUJIAN

Tabel 1. Hasil Pengujian Input Chating Telegram

\begin{tabular}{|c|c|c|}
\hline Input Chatting & Respon BOT & Hasil Respon \\
\hline /unlock & Direspon & Solenoid Doorlock On \\
/lock & Direspon & Solenoid Doorlock Off \\
/lampuOn & Direspon & LED On \\
/lampuOff & Direspon & LED Off \\
\hline
\end{tabular}

Tabel 2. Pengujian proses pada Port Mikrokontroler NodeMCU

\begin{tabular}{|c|c|c|}
\hline PENGUJIAN NODEMCU & Port IC & Keterangan \\
\hline Relay for Solenoid Doorlock & Port D0 & Aktif \\
Relay for LED & Port D1 & Aktif \\
Relay for Buzzer & Port D2 & Aktif \\
Push Button & Port D5 & Aktif \\
\hline
\end{tabular}

Tabel 3. Pengujian Output dengan chatting inputan /unlock

\begin{tabular}{|c|c|c|}
\hline $\begin{array}{c}\text { ITEM } \\
\text { PENGUJIAN }\end{array}$ & $\begin{array}{l}\text { Chatting } \\
\text { Input } \\
\text { “/unlock" }\end{array}$ & Keterangan \\
\hline Modul Relay Kl & Aktif & $\begin{array}{l}\text { Aktif karena mendapatkan sinyal } O n \text { dari } \\
\text { Mikrokontroler }\end{array}$ \\
\hline Modul Relay K2 & - & $\begin{array}{l}\text { Tidak aktif karena tidak mendapatkan } \\
\text { sinyal On dari Mikrokontroler }\end{array}$ \\
\hline Modul Relay K3 & - & $\begin{array}{l}\text { Tidak aktif karena tidak mendapatkan } \\
\text { sinyal On dari Mikrokontroler }\end{array}$ \\
\hline Solenoid Doorlock & Aktif & $\begin{array}{l}\text { Menyala karena power } 12 \mathrm{~V} \text { sudah } \\
\text { disalurkan oleh relay } \mathrm{K} 1\end{array}$ \\
\hline$L E D$ & - & $\begin{array}{l}\text { Tidak aktif karena power } 12 \mathrm{~V} \text { belum } \\
\text { disalurkan oleh relay } \mathrm{K} 2\end{array}$ \\
\hline Buzzer Fault & - & $\begin{array}{l}\text { Tidak aktif karena power } 12 \mathrm{~V} \text { belum } \\
\text { disalurkan oleh relay } \mathrm{K} 3\end{array}$ \\
\hline
\end{tabular}


Tabel 4. Pengujian Output dengan chatting input /lampuOn

\begin{tabular}{|c|c|c|}
\hline $\begin{array}{c}\text { ITEM } \\
\text { PENGUJIAN }\end{array}$ & $\begin{array}{c}\text { Chating } \\
\text { Input } \\
\text { “/lampuOn" }\end{array}$ & Keterangan \\
\hline Modul Relay K1 & - & $\begin{array}{l}\text { Tidak aktif karena tidak mendapatkan } \\
\text { sinyal On dari Mikrokontroler }\end{array}$ \\
\hline Modul Relay K2 & Aktif & $\begin{array}{l}\text { Aktif karena mendapatkan sinyal } O n \\
\text { dari Mikrokontroler }\end{array}$ \\
\hline Modul Relay K3 & - & $\begin{array}{l}\text { Tidak aktif karena tidak mendapatkan } \\
\text { sinyal On dari Mikrokontroler }\end{array}$ \\
\hline Solenoid Doorlock & - & $\begin{array}{l}\text { Tidak aktif karena power } 12 \mathrm{~V} \text { belum } \\
\text { disalurkan oleh relay } \mathrm{K} 1\end{array}$ \\
\hline$L E D$ & Aktif & $\begin{array}{l}\text { Menyala karena power } 12 \mathrm{~V} \text { sudah } \\
\text { disalurkan oleh relay } \mathrm{K} 2\end{array}$ \\
\hline Buzzer Fault & - & $\begin{array}{l}\text { Tidak aktif karena power } 12 \mathrm{~V} \text { belum } \\
\text { disalurkan oleh relay } \mathrm{K} 3\end{array}$ \\
\hline
\end{tabular}

\section{ANALISIS HASIL}

Dari serangkaian tahap pengujian pada prototype sistem Smart Home dengan konsep IOT (Internet Of Thing) berbasis NodeMCU dan telegram. Terdapat beberapa analisis hasil terkait pengujian yang telah diterapkan.

Pada proses input yang pertama BOT Telegram berhasil merespon data perintah input chatting yang telah diprogram pada memori data base. Hal ini terlihat ketika perintah input chatting dapat direspon dan akan memproses perintah program yang telah dibuat.

Pada proses input yang kedua limit switch berhasil menyalurkan sinyal input NC atau sinyal input NO memori data base. Hal ini terbukti ketika sinyal input NC diterima, mikrokontroller memproses serangkaian perintah proses kerja sesuai dengan fungsi perintah program yang telah dibuat.

Kelemahan pada proses input satu dan dua ada ketika koneksi melambat atau memutus, hal ini terjadi karena mikrokontroler modul ESP8266 menerima 
kecepatan koneksi yang buruk sehingga penyaluran sinyal input dan penyampaian konfirmasi sinyal output menjadi delay.

Pengujian output berjalan sesuai dengan kondisi perintah kerja. Ketika BOT telegram merespon perinntah input chatting maka output dapat bekerja aktif sesuai dengan fungsinya.

\section{KESIMPULAN}

Berdasarkan hasil analisa dan pembahasan, dapat ditarik kesimpulan sebagai berikut:

1. Untuk merancang pada prototype sistem Smart Home dengan konsep IOT (Internet Of Thing) menggunakan smartphone sebagai komponen input, Chip ESP8266, mikrokontroler sebagai komponen pemroses, lampu dan Solenoid Doorlock sebagai komponen output.

2. Untuk mengimplementasi Untuk merancang pada prototype sistem Smart Home dengan konsep IOT (Internet Of Thing) menggunakan aplikasi telegram messenger sebagai kontrol dari sistem yang sudah terkoneksi dengan jaringan internet.

\section{DAFTAR PUSTAKA}

Arafat. (2013). "Sistem Pengamanan Pintu Rumah Berbasis Internet Of Things Dengan ESP8266.” Technologia. Vol.7 No. (4). 262-267

Alfannizar I dan Rahayu Y. (2018). "Perancangan dan Pembuatan Alat Home Electricity Based Home Appliance Controller Berbasis Internet of Things." Jom FTEKNIK. Vol. 5. No. (1). 1-6

Aji S. P. (2017). “Alat Monitoring Tetesan Infus Menggunakan Web Secara Onlineberbasis Esp8266 Dengan Pemrograman Arduino Ide." Tugas Akhir. 1-10

Irfan, Unang, Rohmat. (2018). "Internet of Things: Sistem Keamanan Rumah Berbasis Raspberry Pi dan Telegram Messenger." ELKOMIKA. Vol. 6. No. (1). 1-15

Rachman, Azam, Anindito. (2017). "Sistem Pemantau \& Pengendalian Rumah Cerdas Menggunakan Infrastuktur Internet Messaging." JURNAL LINK. Vol. 26. No. (1). 1-6

Mudjanarko, Winardi, Limantara. (2017). "Pemanfaatan Internet Of Things (IOT) Sebagai Solusi Manejemen Transportasi Kendaraan Sepeda 
Motor." Prosiding Seminar Nasional Aplikasi Prasarana Wilayah X (ATPW). 151-164

Ramakumbo, A. G. (2012). "Magnetic Door Lock Menggunakan Kode Pengaman Berbasis Atmega 328.” Tugas Akhir pada Universitas Negeri Yogyakarta.

Pasaribu, B. M. (2017). "Kunci Pintu dengan Smartphone Android Menggunakan NFC - Enabled Dan Password." Tugas Akhir pada Politeknik Negeri Batam.

http://si.ittelkom-pwt.ac.id/2018/05/16/tantangan-yang-mengintip-dalam-internetof-things, 2018.

https://guide.servify.in/iot-internet-of-things-explained, 2017

https://de.wikipedia.org/wiki/NodeMCU, 2014

https://id.aliexpress.com/item/free-shipping-1pcs-2-channel-relay-module-5V-2channel-relay-modules-5 VDC-2-road-relay, 2017

https://www.ebay.com/p/08371-DC-12v-8w-Open-Frame-Type-Solenoid-forElectric-Door-Lock-TS/1469175991

https://medium.com/@ngrjs/creating-a-telegram-bot-using-python-9d11a43a8d2, 2016

https://www.google.com/search?q=rangkaian+led

globalsources.com 